\title{
SCIENTIFIC REP RTS OPEN Corrigendum: A proteinaceous organic matrix regulates carbonate mineral production in the marine teleost intestine
}

\author{
Kevin L. Schauer, Christophe M. R. LeMoine, Adrian Pelin, Nicolas Corradi, M. Danielle McDonald, \\ Wesley C. Warren \& Martin Grosell
}

Scientific Reports 6:34494; doi: 10.1038/srep34494; published online 03 October 2016; updated on 19 June 2017

M. Danielle McDonald was omitted from the author list in the original version of this Article. This has been corrected in the PDF and HTML versions of the Article, as well as the Supplementary Information file that accompanies the Article.

The Acknowledgments section now reads:

"The authors wish to thank the staff at the Colorado State University Proteomics and Metabolomics Facility for their assistance with the mass spectrometry analyses presented here as well as Patricia Blackwelder at the University of Miami Center for Advanced Microscopy for her assistance with the electron microscopy. K.L.S. is supported in part by the University of Miami Maytag Fellowship. The transcriptome work was supported by NIH grant R24 RR032658-01 to W.C.W., McDonnell Genome Institute at Washington University School of Medicine. M.D.M. was supported by NSF (IOS-0920547). M.G. is a Maytag Chair of Ichthyology and is supported by NSF (IOS 1146695)".

The author contribution statement now reads:

"K.L.S. and M.G. designed the experiments. K.L.S. performed the experiments, analyzed the data, and wrote the manuscript. M.G., M.D.M., W.C.W. and C.M.R.L. designed and executed transcriptomic experiments. W.C.W. performed the transcriptome sequencing. C.M.R.L., A.P. and N.C. analyzed, and assembled the transcriptomic data. M.G., C.M.R.L., A.P., W.C.W. and N.C. provided edits to a draft manuscript; M.G. approved the final version".

(c) (i) This work is licensed under a Creative Commons Attribution 4.0 International License. The images or other third party material in this article are included in the article's Creative Commons license, unless indicated otherwise in the credit line; if the material is not included under the Creative Commons license, users will need to obtain permission from the license holder to reproduce the material. To view a copy of this license, visit http://creativecommons.org/licenses/by/4.0/

(c) The Author(s) 2017 